\title{
Simple Life Review for Terminally Ill Cancer Patients with Low Cognitive Function
}

\author{
Michiyo Ando ${ }^{1}$, Hiromi Minota ${ }^{2}$, Chika Shibukawa ${ }^{2}$, Haruko Kira ${ }^{3}$ \\ ${ }^{1}$ Faculty of Nursing, St. Mary’s College, Faculty of Nursing, Kurume City, Japan; ${ }^{2}$ St. Mary’s Hospital, Fukuoka, Japan; ${ }^{3}$ Kurume \\ University, Fukuoka, Japan. \\ Email: andou@st-mary.ac.jp
}

Received July 27 ${ }^{\text {th }}$, 2012; revised August 31 $1^{\text {st }}$, 2012; accepted September $10^{\text {th }}$, 2012

\begin{abstract}
Objective: The aims of the study were to develop a Simple Life Review Interview as psychotherapy for terminally ill cancer patients with slight cognitive impairment, and to examine the feasibility and effects of this approach on spiritual well-being and quality of life. Methods: The participants were 5 terminally ill cancer patients in a palliative care unit. They completed questionnaires for the Functional Assessment of Chronic Illness Therapy-Spiritual (FACIT-Sp) scale, Good Death Inventory (Hope, Burden, Human Relationship, Respect as an Individual), and Distress and Impact Thermometer. Results: The Simple Life Review Interview consisted of viewing a DVD and reviewing the patient's life using questions that are applicable to terminally ill cancer patients with slight cognitive impairment. Overall, the FACIT-Sp score and the scores for Hope, Human Relationship, and Respect as an Individual on the Good Death Inventory increased, while the Burden score and the Distress and Impact Thermometer score decreased. However, there were some exceptions to these results. Conclusion: The Simple Life Review is feasible for terminally ill cancer patients with some cognitive impairments, and might be effective for improving spiritual well-being, Good Death, and psychological distress in these patients.
\end{abstract}

Keywords: Psychotherapy; Simple Life Review; Terminally Ill Patients; Spiritual Well-Being; Quality of Life

\section{Introduction}

Palliation of psycho-existential suffering in terminally ill cancer patients is of great importance because it is related to quality of life, good death, depression [1], desire for a hastened death, hopelessness, and suicidal ideation [2]. It has been reported that $17 \%$ of patients have a strong desire for a hastened death and $16 \%$ meet criteria for a major depressive episode [3]. Desire for a hastened death was significantly associated with clinical depression and hopelessness. Murata \& Morita [4] defined psychoexistential suffering as pain caused by extinction of being and meaning of self through loss of relationships with others, loss of autonomy, or loss of a future. In this model, psycho-existential suffering has sense of meaning as a core concept, and ten domains of quality of life (QOL) have been proposed as important factors from a study of good death [5].

Review therapy is a psychotherapy that is used for psycho-existential suffering and elevation of QOL. We have examined this approach through exploration of the feasibility and efficacy of 4-week formal reminiscence therapy in terminally ill cancer patients [6]. This study demonstrated a positive effect on spiritual well-being [7], but about $30 \%$ of the patients did not complete the study due to rapid physical deterioration. We then developed a novel psychotherapy, the Short-Term Life Review, comprising two sessions over 1 week, and explored its feasibility and efficacy using a pre-post study design [8]. The results show high feasibility and efficacy for spiritual well-being measured by the Functional Assessment of Chronic Illness Therapy-Spiritual scale (FACIT-Sp) [9], and the Good Death (Hope, Burden, Life Completion, and Preparation) scale in a randomized controlled trial.

An examination of the ease of answering the 8 questions in the Short-Term Life Review gave mixed results. These questions are 1) What is the most im- portant thing in your life and why? 2) What are the most vivid or impressive memories in your life? 3) In your life, what event or person affected you most? 4) What is the most important role you played in your life? 5) What is the proudest moment in your life? 6) Is there anything about you that your family needs to know? 7) Are there things you want to tell them and are there things you want them to remember? 8) What advice or words of guidance do you have for the important people in your life or for the younger generation? We found that questions 1 ), 2), and 
4) were easy to answer, whereas other questions were more difficult [10].

It is also important to recognize that terminally ill cancer patients are often sedated and may have decreased cognitive function, particularly with the increased number of elderly patients with dementia. Therefore, we developed a new kind of life review, the Simple Life Review, for patients with low cognitive function. In the present study, we assessed the feasibility of the Simple Life Review and examined the efficacy of this therapy for spiritual well-being and QOL.

\section{Patients and Methods}

\subsection{Participants}

The participants were cancer patients from the Palliative Care Units (PCUs) of general hospitals in Western Japan. The inclusion criteria were 1) incurable cancer, in the PCU, and duration in the PCU between 2 and 4 weeks; 2) ability to communicate; 3) age > 20 years old. The exclusion criteria were 1) severe pain or physical symptoms diagnosed by the primary doctor; 2) cognitive impairment such as dementia or consciousness disturbance; 3) difficult family problems such as those with regard to inheritance of property, conflicts about the patient's funeral among family members, and difficulty with reconciliation of past problems between the patient and their family members. Regarding selection of participants, a head nurse in each hospital introduced the study to patients who met the inclusion criteria and did not meet the exclusion criteria. A therapist then explained the research in detail after a patient had shown interest in participation. The study was approved by the ethical committee of St. Mary's Hospital and St. Mary's College.

\subsection{Outcome Measures}

We chose the sense of meaning measured by the FACIT-Sp scale as the primary endpoint. The validity and reliability of the Japanese version of the FACIT-Sp are well established [11]. The FACIT-Sp consists of two domains, meaning of life and religious issues, but only the meaning of life domain was used, since an effect of the Short-Term Life review on religious issues in one week was unlikely. The meaning of life domain includes 8 items and is scored on a 5-point scale (range, 0 - 4). The total range of the FACIT-Sp is 0 to 32, and high scores indicate an elevated sense of meaning of life or a peaceful state of mind. The $\alpha$ reliability coefficient of the 8 items was 0.87 .

To explore the effects of the Simple Life Review on patient-perceived good death, we used several items from the Good Death Inventory [5]. This is a 28-item questionnaire with 10 core domains, of which we used four: "Hope", "Burden", "Good Relationships", and "Being
Respected as an Individual". "Hope" is measured using a 7-point numeric rating scale for the statement, "I have some pleasure in daily life", with a high score indicating an elevated sense of hope (range, 1 - 7). Similarly, the "Good Relationships" and "Being Respected as an Individual" domains consist of several items and a high score indicates a positive response. Conversely, "Burden" is evaluated using a 7-point numeric rating scale for the statement, "I am distressed that I am being a burden to family members", with a high score indicating an elevated feeling of being burdensome (range, 1 - 7). To measure distress, we used the Distress and Impact Thermometer (DIT) [12]. Performance status was measured using the ECOG PSR scale, which is a single-item rating of five activity levels from 0 (fully active) to 4 (completely disabled).

\subsection{Interventions}

In the Simple Life Review, we used 2 interview sessions. The contents are shown in Table 1. A DVD of beautiful seasonal scenes and human development was made to promote memories in the patients. A sample of the contents of the DVD is shown in Figure 1. In the first session, the patient viewed the DVD with the therapist and reviewed their life with an interviewer who was trained to conduct the therapy. Each interview session lasted about 30 minutes, with a 1-week interval between the

Table 1. Contents of the simple life review interview.

\begin{tabular}{cl}
\hline Session & Contents \\
\hline & DVD \\
& Beautiful nature scenes in four seasons (spring, \\
& summer, autumn, winter) \\
& Main events in Japan (e.g. festival, New Years Day, \\
& hanami ) \\
& Main events in human development \\
& Questions (important things, impressive memory, \\
& role in your life) \\
& Viewing patients album \\
& Confirmation of album contents \\
&
\end{tabular}

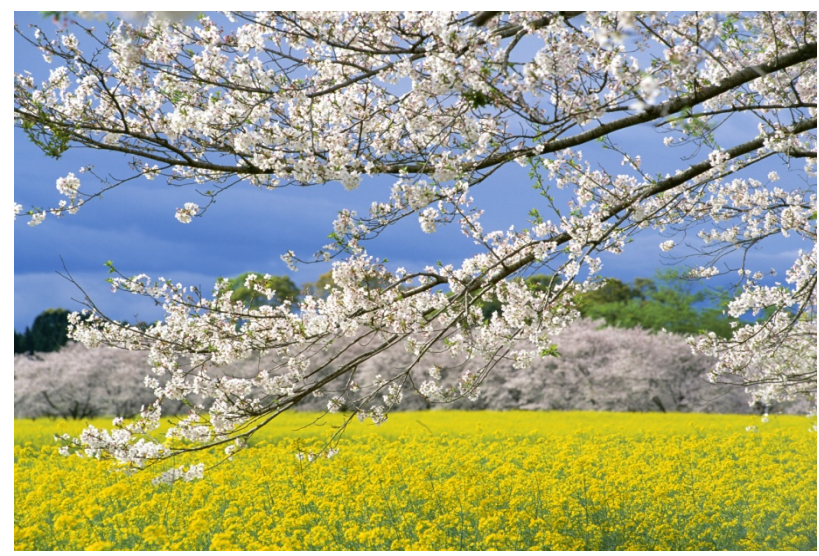

Figure 1. Scene of the DVD in the simple life review. 
first and second sessions. The following questions were asked with reference to autobiography life-review therapy, in which clients review their lives. In the first session, the patients were asked: 1) What is the most important thing in your life and why? 2) What are the most impressive memories in your life? 3) What is the most important role you played in your life?

The patient's narratives were recorded and the interview was transcribed verbatim. The therapist made a simple album including key words from the answer to each question, which were selected through a discussion between the patient and the therapist. Key words included both positive and negative elements of the interview. In the second session, the patient and therapist viewed the album together and agreed upon the contents. The therapist encouraged the patient to feel continuity of self from the past to the present, to accept life completion, and to be satisfied with their life. After the second session, the therapist presented the album to the patients. Some of the patients also made art.

\section{Results}

\subsection{Overall Findings}

All five patients completed the therapy. We call each patient as ID number from a patient 01 to a patient 05 . The score of each scale was shown in Table 2. The FACIT-Sp score increased from $24.8 \pm 16.1$ to $34.8 \pm$ 7.79, the Hope score increased from $5.17 \pm 1.57$ to $5.5 \pm$ 1.28 , the Burden score decreased from $3.58 \pm 1.64$ to $3.08 \pm 2.17$, the Good Relationships score increased from $5.33 \pm 1.25$ to $5.92 \pm 0.86$, and the Being Respected as an Individual score increased from $5.04 \pm 1.22$ to $5.54 \pm$ 1.41. The Distress score decreased from $6.4 \pm 1.34$ to 2.2 \pm 1.48 and the Impact score decreased from $6 \pm 1.41$ to $3.2 \pm 2.59$. The scores for individual patients are shown in Figures 2-8. A brief review of the background of each patient is given below.

\subsection{Characteristics of the Patients}

Patient 01 was a woman aged 70 years old. She was religious, had strong beliefs, and had taught many

Table 2. Scores on the each scale.

\begin{tabular}{cccc}
\hline & & Pre & Post \\
\hline \multirow{2}{*}{ FACIT-Sp } & Hope & $5.17 \pm 1.6$ & $5.5 \pm 1.28$ \\
\multirow{2}{*}{$\begin{array}{c}\text { Good death } \\
\text { inventory }\end{array}$} & Being a burden & $3.58 \pm 1.6$ & $3.08 \pm 2.2$ \\
& Good relationships & $5.33 \pm 1.3$ & $5.92 \pm 0.9$ \\
Distress impact & Being respected & $5.04 \pm 1.2$ & $5.54 \pm 1.4$ \\
thermometer & Distress & $6.4 \pm 1.3$ & $2.2 \pm 1.5$ \\
\hline
\end{tabular}

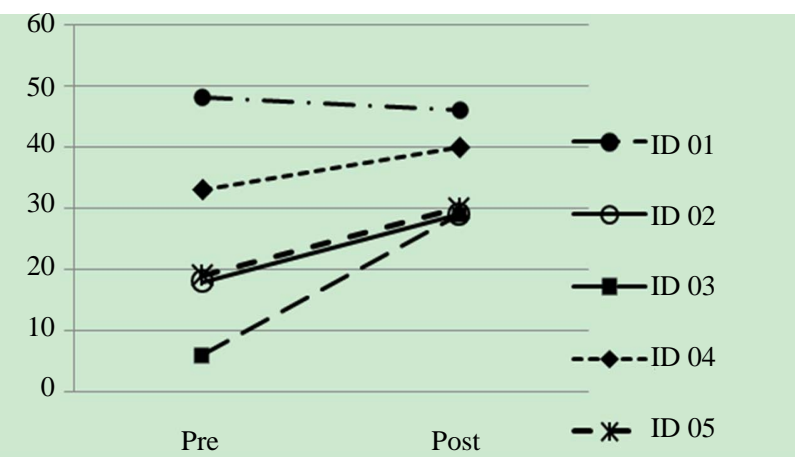

Figure 2. Scores of FACIT-Sp.

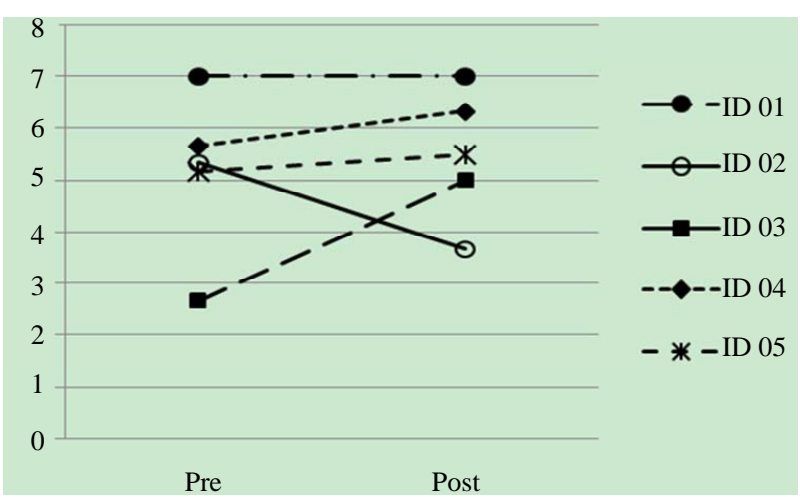

Figure 3. Score of hope

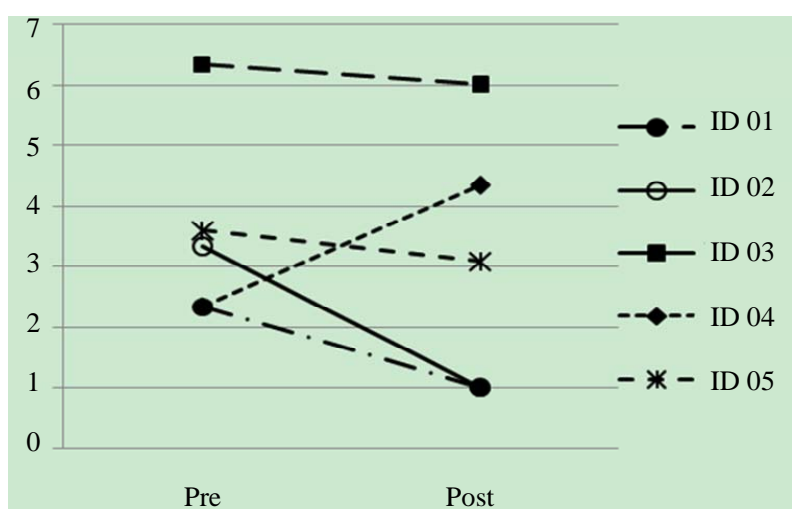

Figure 4. Socres of burden

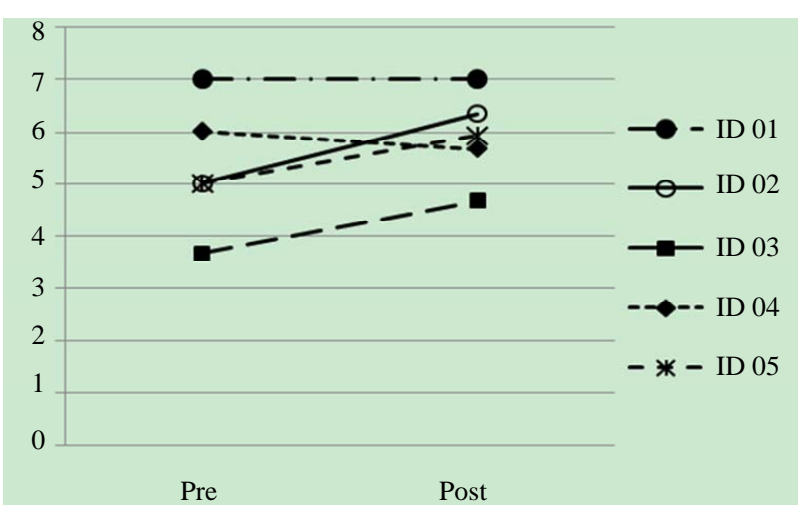

Figure 5. Scores of good relationships 


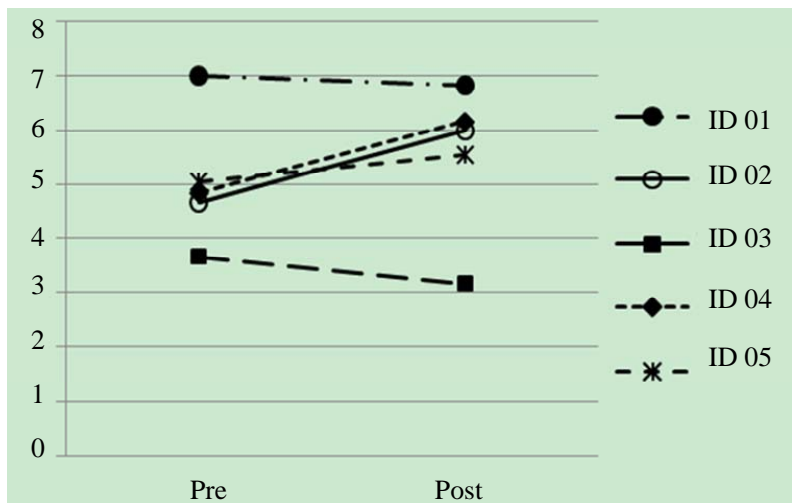

Figure 6. Score of being respected

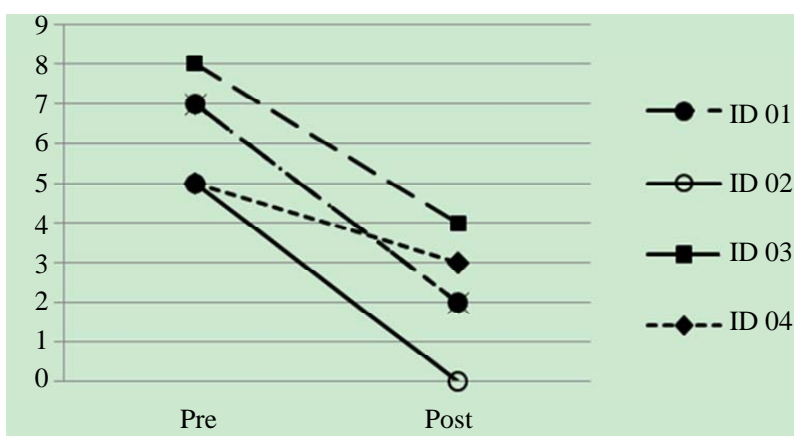

Figure 7. Socres of distress.

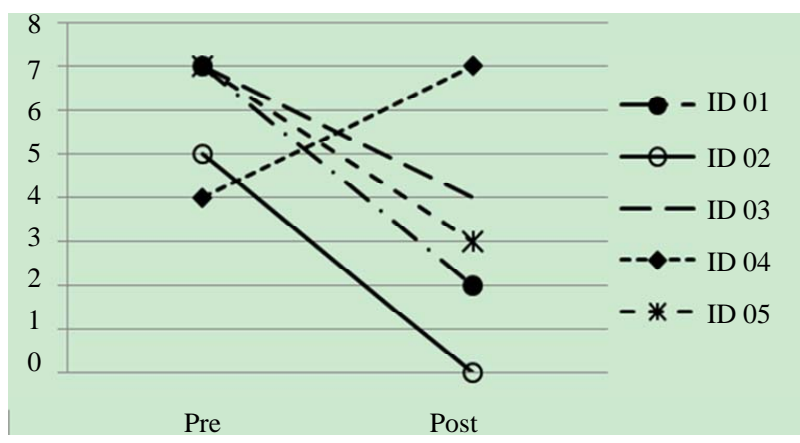

Figure 8. Socres of impact.

students. The most important things in her life were her self-growth and having a clear role. Through the life review, she recognized her achievements and was satisfied with her life. Thus, her FACIT-Sp, Hope, Human Relationships, and Being Respected as Individual scores were the highest among all the scores.

Patient 02 was a 60 -year-old man who was married, but did not have a family and had lived independently. Through the life review, he remembered his achievements at work and his enjoyment of time spent with friends. Thus, the FACIT-Sp and Human Relationships scores increased and the Burden score decreased. However, he still hoped to work on the internet and to go walking in nature, but since these activities were not possible, his Hope score decreased.
Patient 03 was a 60 -year-old housewife with grown-up children and grandchildren. She evaluated her life very moderately, and her FACIT-Sp, Human Relationship, and Being Respected scores were lower than others, although the Burden, Distress, and Impact scores were also low. Through the life review, she indicated satisfaction with her life with regard to her family and grandchildren. She was delighted to see her grandchildren at the hospice, and the Hope score increased greatly.

Patient 04 was a 40-year-old woman who was unmarried and had only her mother as family. Through the life review, she recognized her independent life, although she had unresolved problems with her parents. Advancement of her disease had an impact on her and she felt like a burden to others. Thus, the Burden score increased.

Patient 05 was a 70 -year-old woman. She was pessimistic and had a negative outlook in the first session. However, although she talked about negative things, she continued with her life stories and found some happy memories. In the second session, her physical state was better than in the first session, and she narrated well.

\section{Discussion}

\subsection{Effectiveness of the Simple Life Review}

Five patients completed the Simple Life Review Interview. Participation was simplified by the ease of viewing the DVD, and the clarity of the contents of the DVD seemed to promote the efficacy of the review. All of the participants had a good impression of the DVD. This suggests that preparation of the DVD was particularly useful since it allowed the therapy to be started easily.

The FACIT-Sp score increased for all patients, despite some having problems such as decreased physical strength. This indicates that the Simple Life Review is appropriate for terminally ill cancer patients with low cognitive function. The finding that the life review is effective for spiritual well-being supports a previous study using the Short-Term Life Review [10]. This therapy may be useful for spiritual well being because it helps patients to remember their lives through questions. This allows the patient to confirm the important moments, achievements and roles in their life, and to be satisfied with their life through integrating these memories. The patients can praise their own lives and reach a level of satisfaction. Moreover, the Simple Life Review or the Short Term Life Review may include milder questions compared to those described by Chochinove et al. [13].

On the Good Death scale, there were overall increases in the Hope, Good Relationships, and Being Respected scores, and an overall decrease in the Burden score after performance of the Simple Life Review. This suggests that this therapy may have an effect on Good Death in terminally ill cancer patients with low cognitive function. 
However, there were some exceptions. The Burden score of Patient 04 increased because of the impact of disease progression and her increased dependency on others, particularly because she had lived independently. Thus, the Simple Life Review may not relieve a burden that is caused by physical problems. The Hope score for Patient 02 decreased because his hopes for connecting to the internet or walking in the fields were hard to realize in the palliative care unit. Therefore, if a patient's hope is practical but cannot be realized, the Simple Life Review may not be effective.

The efficacy for Good Death is consistent with previous studies [10,14-16]. The decreased Distress and Impact scores in all patients except Patient 04 suggest that the Simple Life Review may be effective for decreasing psychological distress and impact on daily life. Finally, we note that Patient 01 drew a picture of her life and that Patient 04 made a collage by pasting of photographs. These forms of art might be useful in allowing patients to express their feelings and thoughts.

\subsection{Limitations}

The results cannot be generalized, since the number of participants was small and the study was performed only in a one institution. Validation of the findings will require a further study that includes more participants.

\subsection{Conclusion}

We conclude that the Simple Life Review is feasible for use with terminally ill cancer patients with some cognitive impairments. This therapy may be effective for improving spiritual well-being, Good Death, and psychological distress in these patients.

\section{Acknowlegements}

This research is supported by Fukuoka Foundation for Sound Health.

\section{REFERENCES}

[1] C. J. Nelson, B. Rosenfeld, W. Breitbart and M. Galietta, "Spirituality, Religion, and Depression in the Terminally Ill,” Psychosomatics, Vol. 43, No. 3, 2002, pp. 213-220. doi:10.1176/appi.psy.43.3.213

[2] C. S. McClain, B. Rosenfeld and W. Breitbart, "Effect of Spiritual Well-Being on End-of-Life Despair in Terminally-Ill Patients," Lancet, Vol. 361, No. 9369, 2003, pp. 1603-1607. doi:10.1016/S0140-6736(03)13310-7

[3] W. Breitbart, B. Rosenfeld, H. Pessin, M. Kaim, J. Funesti-Esch, M. Galietta, et al., "Depression, Hopelessness, and Desire for Hastened Death in Terminally Ill Patients with Cancer," Journal of the American Medical Association, Vol. 284, No. 22, 2000, pp. 2907-2911.

doi:10.1001/jama.284.22.2907
[4] H. Murata and T. Morita, "Conceptualization of Psycho-Existential Suffering by the Japanese Task Force: The First Step of a Nationwide Project," Palliative and Supportive Care, Vol. 4, No. 3, 2006, pp. 279-285. doi:10.1017/S1478951506060354

[5] M. Miyashita, T. Morita, K. Sato, K. Hirai, Y. Shima and Y. Uchitomi, "Good Death Inventory: A Measure for Evaluating Good Death from the Bereaved Family Member's Perspective," Journal of Pain and Symptom Management, Vol. 35, No. 5, 2008, pp. 486-498. doi:10.1016/j.jpainsymman.2007.07.009

[6] M. Ando, A. Tsuda and T. Morita, "Life Review Interviews on the Spiritual Well-Being of Terminally Ill Cancer Patients," Supportive Care in Cancer, Vol. 15, No. 2, 2007, pp. 225-231.

[7] B. V. Wegberg, M. Bacchi, P. Heusser, S. Helwig, R. Schaad, E. V. Rohr, et al. "The Cognitive-Spiritual Dimension: An Important Addition to the Assessment of Quality of Life: Validation of a Questionnaire (SELT-M) in Patients with Advanced Cancer," Annals of Oncology, Vol. 9, No. 10, 1998, pp. 1091-1096. doi:10.1023/A:1008343219970

[8] M. Ando, T. Morita, T. Akechi and T. Okamoto, (Japanese Task Force for Spiritual Care), "Efficacy of ShortTerm Life Review Interviews on the Spiritual Well-Being of Terminally Ill Cancer Patients," Journal of Pain and Symptom Management, Vol. 39, No. 6, 2010, pp. 993102. doi:10.1016/j.jpainsymman.2009.11.320

[9] A. H. Peterman, G. Fitchett, M. J. Brady, L. H. Pharm and D. Cella, "Measuring Spiritual Well-Being in People with Cancer: The Functional Assessment of Chronic Illness Therapy-Spiritual Well-Being Scale (FACIT-Sp),” Annals of Behavioral Medicine, Vol. 24, No. 1, 2002, pp. 49-58. doi:10.1207/S15324796ABM2401_06

[10] M. Ando, T. Morita and T. Akechi, "Factors in Narratives to Questions in the Short-Term Life Review Interviews of Terminally Ill Cancer Patients and Utility of the Questions," Palliative and Supportive Care, Vol. 10, No. 2, 2012, pp. 1-8

[11] W. Noguchi, T. Ohno, S. Morita, O. Aihara, H. Tsujii, K. Shimozuma, et al. "An Investigation of Reliability and Validity of the Japanese Version of the Functional Assessment of Chronic Illness Therapy-Spiritual (FACITSp)," Japanese Journal of General Hospital Psychiatry, Vol. 16, No. , 2004, pp. 42-47.

[12] N. Akizuki, S. Yamawaki, T. Akechi, T. Nakano and Y. Uchitomi, "Development of an Impact Thermometer for use in Combination with the Distress Thermometer as a Brief Screening Tool for Adjustment Disorders and/or Major Depression in Cancer Patients," Journal of Pain and Symptom Management, Vol. 29, No. 1, 2005, pp. 9199. doi:10.1016/j.jpainsymman.2004.04.016

[13] H. M. Chochinov, T. Hack, T. Hassard, L. J. Kristjanso, S. McClement and M. Harlos, "Dignity Therapy: A Novel Psychotherapeutic Intervention for Patients near the End of Life," Journal of Clinical Oncology, Vol. 23, No. 24, 2005, pp. 5520-5525. doi:10.1200/JCO.2005.08.391

[14] M. Miyashita, M. Sanjyo, T. Morita, K. Hirai and Y. Uchitomi, "Good Death in Cancer Care: A Nationwide 
Quantitative Study,” Annals of Oncology, Vol. 18, No. 6, 2007, pp. 1090-1097. doi:10.1093/annonc/mdm068

[15] M. Miyashita, T. Morita, K. Sato, K. Hirai, Y. Shima and Y. Uchitomi, "Factors Contributing to Evaluation of a Good Death from the Bereaved Family Member's Perspective," Psycho-Oncology, Vol. 17, No. 6, 2008, pp. 612-620. doi:10.1002/pon.1283
[16] K. E. Steinhauser, N. A. Christakis, E. C. Clipp, M. McNeilly, L. McIntyre L and J. A. Tulsky, "Factors Considered Important at the End of Life by Patients, Family, Physicians, and Other Care Providers," Journal of the American Medical Association, Vol. 284, No. 19, 2000, pp. 2476-2482. doi:10.1001/jama.284.19.2476 